\title{
Best BLAST hit alone cannot be used as evidence of fraud
}

\author{
Natalia Díaz-Arce* and Naiara Rodríguez-Ezpeleta* \\ ugartea z/g, 48395 Sukarrieta - Bizkaia, Spain \\ ${ }^{*}$ Corresponding authors: \\ Natalia Díaz-Arce; ndiaz@azti.es \\ Naiara Rodriguez-Ezpeleta; nrodriguez@azti.es
}

AZTI, Marine Research, Basque Research and Technology Alliance (BRTA). Txatxarramendi

ARISING FROM: Blanco-Fernandez et al.: Scientific Reports https://doi.org/10.1038/s41598021-91020-w (2021)

\begin{abstract}
In a recent study, Blanco-Fernandez, et al. ${ }^{1}$ applied molecular tools to authenticate fish products and conclude evidence of "worrying international fraud". They revealed mislabeling in recognizable and unrecognizable fish products labeled as anchovy, hake and tuna commercialized by European companies. Their analyses consisted on extracting DNA from the fish product to be authenticated followed by amplification and sequencing of a suite of DNA markers and on comparing the resulting sequences to the GenBank sequence database using BLAST (Basic Tool Alignment Search Tool) (https://blast.ncbi.nlm.nih.gov/Blast.cgi). By carefully reanalyzing their data, we identify errors in their species identification and conclude that best BLAST hit alone cannot be used as evidence of fraud.
\end{abstract}

\section{Introduction}

Seafood product traceability is essential to detect intentional or unintentional mislabeling and thus helps reducing unreported, unregulated and illegal fishing while enhancing consumer safety ${ }^{2}$. Genetic methods have shown to be powerful for seafood product traceability ${ }^{3}$, in particular, when morphological characteristics cannot be confidently used such as in young age specimens (e.g., juveniles of bigeye and yellowfin tunas are very difficult to distinguish ${ }^{4}$ ) or in closely related species (e.g. black and white anglerfish ${ }^{5}$ ), and specially in processed products (e.g. filleted and canned), where anatomical traits important for fish identification (e.g. head, 
fins, skin) are absent. Accurate genetic based seafood product traceability requires developing approaches that unequivocally discriminate between species, for which it is essential to understand intra-specific variability as well as each species' evolutionary context. In their study, Blanco-Fernandez, et al. ${ }^{1}$ use the best hit of a BLAST search against GenBank to assign species to the sample to be authenticated. Here, by analyzing their BLAST results considering other information, we show that using BLAST alone can lead to erroneous species assignments and thus to conclude fraud when there is not.

\section{Results and Discussion}

One of the striking observations from Blanco-Fernandez et al. is the substitution of albacore (Thunnus alalunga) by Atlantic bluefin tuna (Thunnus thynnus), which is surprising being albacore less than half the price of bluefin tuna (https://www.eumofa.eu/es/home). The authors explain this potential substitution by over-quota-caught bluefin tuna being sold as another species. This is a very strong claim that needs clear evidence to be made. We thus examined the sequences corresponding to those albacore-labelled tuna products (MW557512, MW557513, MW557514) claimed to be mislabelled bluefin tuna due to a best BLAST hit with sequence EU562888, belonging to T. thynnus according to GenBank. Our hypothesis was that the mislabeling, rather than in the seafood products, is in the sequence in GenBank due to the mitochondrial introgression reported between T. alalunga and T. thynnus ${ }^{6}$. Indeed, it has been estimated that approximately $2-3 \%$ of $T$. thynnus individuals have the so-called "alalunga-like" mitochondrial DNA 7 , which has often misled mitochondrial based phylogenetic inferences of the genus Thunnus ${ }^{8}$. This hypothesis was confirmed by a phylogenetic inference including the putatively mislabelled sequences from Blanco-Fernandez, et al. ${ }^{1}$. and their best BLAST hit, as well as representative sequences from $T$. alalunga, $T$. thynnus (including those labelled as "alalunga-like") and T. albacares (Figure 1). The tree shows two clearly differentiated clades: one is exclusively composed by $T$. thynnus sequences, while the other includes $T$. alalunga, $T$. thynnus "alalunga-like" sequences as well as the sequences from the putatively mislabelled products and their best BLAST hit. These results refute the mislabeling of $T$. thynnus products as T. alalunga reported by Blanco-Fernandez, et al. ${ }^{1}$. and, more importantly, invalidate their impactful interpretations and conclusions derived therein. 


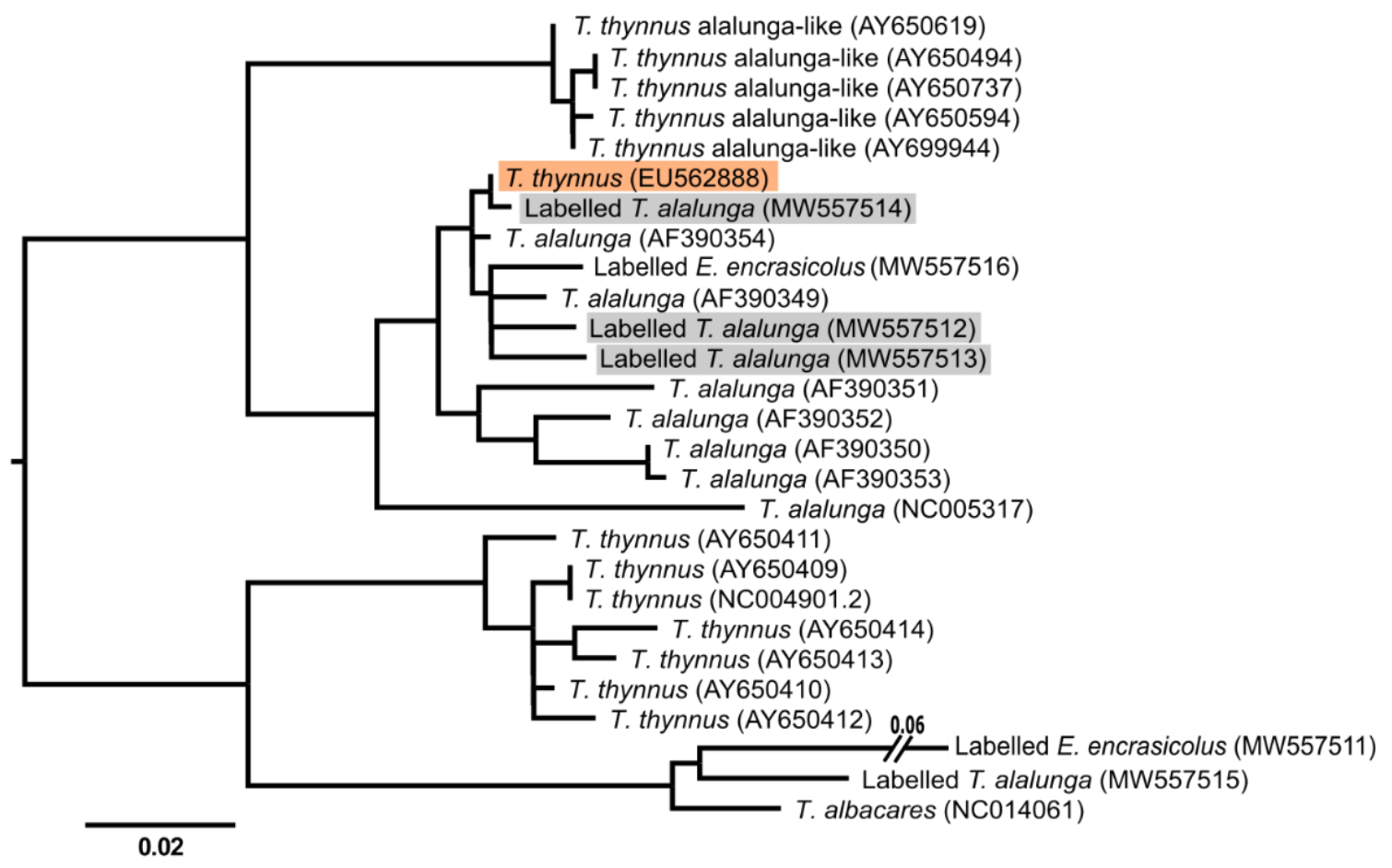

Figure 1. Maximum likelihood phylogenetic inference based on the mitochondrial control region (positions with less than $50 \%$ missing data between 5 to 414 of NC_005317 sequence) including all the available tuna identified sequences from Blanco-Fernandez et al. (MW557511-16) with the ones labelled $T$. alaunga matching to $T$. thynnus labelled in grey, the best BLAST hit $T$. thynnus sequence, shaded in orange, and reference sequences from T. albacares, T. alalunga, T. thynnus and T. thynnus "alalungalike"). The tree is rooted according to Díaz-Arce, et al. ${ }^{8}$.

This clear and easy to detect case could be the tip of the iceberg of errors made in food fraud studies relying solely on best BLAST hits to report mislabeling. Indeed, the bluefin tuna and albacore case is not an isolated one, and instances of genetic introgression that could lead to misidentification are increasingly reported in teleost fishes (e.g., ${ }^{9,10}$ ). Additionally, other factors such as traditionally used morphological characters for species assignment not being diagnostic can also occur and lead to false conclusions regarding mislabelling. This is the case of the black and white anglerfish for which mislabelling was reported ${ }^{11}$ based on the colour of their peritoneum as species diagnostic character, whereas it has recently been discovered that black anglerfish can have white peritoneum ${ }^{12}$ and, thus, reported mislabelling was most likely not so. As shown above, questioning our understanding of the evolutionary history of the species under investigation is essential for seafood fraud studies and could avoid errors such as the one made by Blanco-Fernandez et al. when they report mislabeling of albacore products. Additionally, questioning the ability of BLAST searches to distinguish between closely related species could 
also avoid potential mistakes. Indeed, BLAST results deeply depend on the completeness and accuracy of the reference databases. For example, Blanco-Fernandez, et al. ${ }^{1}$. reported mislabeling between Merluccius polli and M. paradoxus/capensis based on best BLAST hit. Yet, this result was obtained thanks to $M$. polli sequences covering their target region being present in the GenBank. Interestingly, had these sequences, which were submitted to GenBank by the same team ${ }^{13}$, not been available, these $M$. paradoxus/capensis labelled products would have been assigned to $M$. merluccius based on their best BLAST hit. This is due to the next best BLAST hit with other M. polli sequences not covering their whole target region (Table 1). Instead, building a phylogenetic tree would have led to the right conclusion in both cases (Figure 2), further highlighting the power of phylogenies over BLAST searches for species assignment.

Table 1. Best BLAST hits of sequence MW557504 labelled M. paradoxus/capensis ranked according to obtained E value and percentage of identity. Green and yellow indicate best overall BLAST hit if the Machado-Schiaffino, et al. ${ }^{13}$ sequences (in bold) were not present in GenBank and best M. polli BLAST hit. Searches using sequence MW557505 also labeled as M. paradoxus/capensis provided virtually identical results.

\begin{tabular}{|c|c|c|c|c|}
\hline Species & Accession & E value & Query Cover & Percent identity \\
\hline Merluccius polli & EF362877.1 & 0 & $100 \%$ & 100 \\
\hline Merluccius polli & EF362875.1 & 0 & $100 \%$ & 99.76 \\
\hline Merluccius polli & EF362876.1 & 0 & $100 \%$ & 99.52 \\
\hline Merluccius paradoxus & EF362879.1 & 0 & $100 \%$ & 98.32 \\
\hline Merluccius paradoxus & EF362878.1 & 0 & $100 \%$ & 98.08 \\
\hline Merluccius capensis & EF362863.1 & 0 & $100 \%$ & 97.36 \\
\hline Merluccius merluccius & EF362872.1 & 0 & $100 \%$ & 97.12 \\
\hline Merluccius capensis & EF362865.1 & 0 & $100 \%$ & 97.12 \\
\hline Merluccius merluccius & AF232846.1 & 0 & $100 \%$ & 97.12 \\
\hline Merluccius merluccius & AF232845.1 & 0 & $100 \%$ & 97.12 \\
\hline Merluccius capensis & EF362862.1 & 0 & $100 \%$ & 97.12 \\
\hline Merluccius merluccius & MT410897.1 & 0 & $100 \%$ & 96.88 \\
\hline Merluccius merluccius & EF362874.1 & 0 & $100 \%$ & 96.88 \\
\hline Merluccius merluccius & EF362871.1 & 0 & $100 \%$ & 96.88 \\
\hline Merluccius merluccius & AF232848.1 & 0 & $100 \%$ & 96.88 \\
\hline Merluccius merluccius & AF232847.1 & 0 & $100 \%$ & 96.88 \\
\hline Merluccius merluccius & AF232844.1 & 0 & $100 \%$ & 96.88 \\
\hline Merluccius merluccius & AF232843.1 & 0 & $100 \%$ & 96.88 \\
\hline Merluccius merluccius & AF232841.1 & 0 & $100 \%$ & 96.88 \\
\hline Merluccius merluccius & AF232840.1 & 0 & $100 \%$ & 96.88 \\
\hline \multicolumn{5}{|c|}{--1no other M. polli in best 100 blast hits] } \\
\hline Merluccius polli & AY850718.1 & 8.00E-93 & $44 \%$ & 99.46 \\
\hline Merluccius polli & AY850719.1 & $1.00 \mathrm{E}-91$ & $44 \%$ & 98.92 \\
\hline Merluccius polli & AY850722.1 & $2.00 \mathrm{E}-88$ & $44 \%$ & 98.39 \\
\hline Merluccius polli & AF112254.1 & 2.00E-69 & $33 \%$ & 100 \\
\hline Merluccius polli & AY850721.1 & $4.00 \mathrm{E}-65$ & $32 \%$ & 98.55 \\
\hline Merluccius polli & AY850720.1 & $4.00 E-65$ & $32 \%$ & 98.55 \\
\hline
\end{tabular}




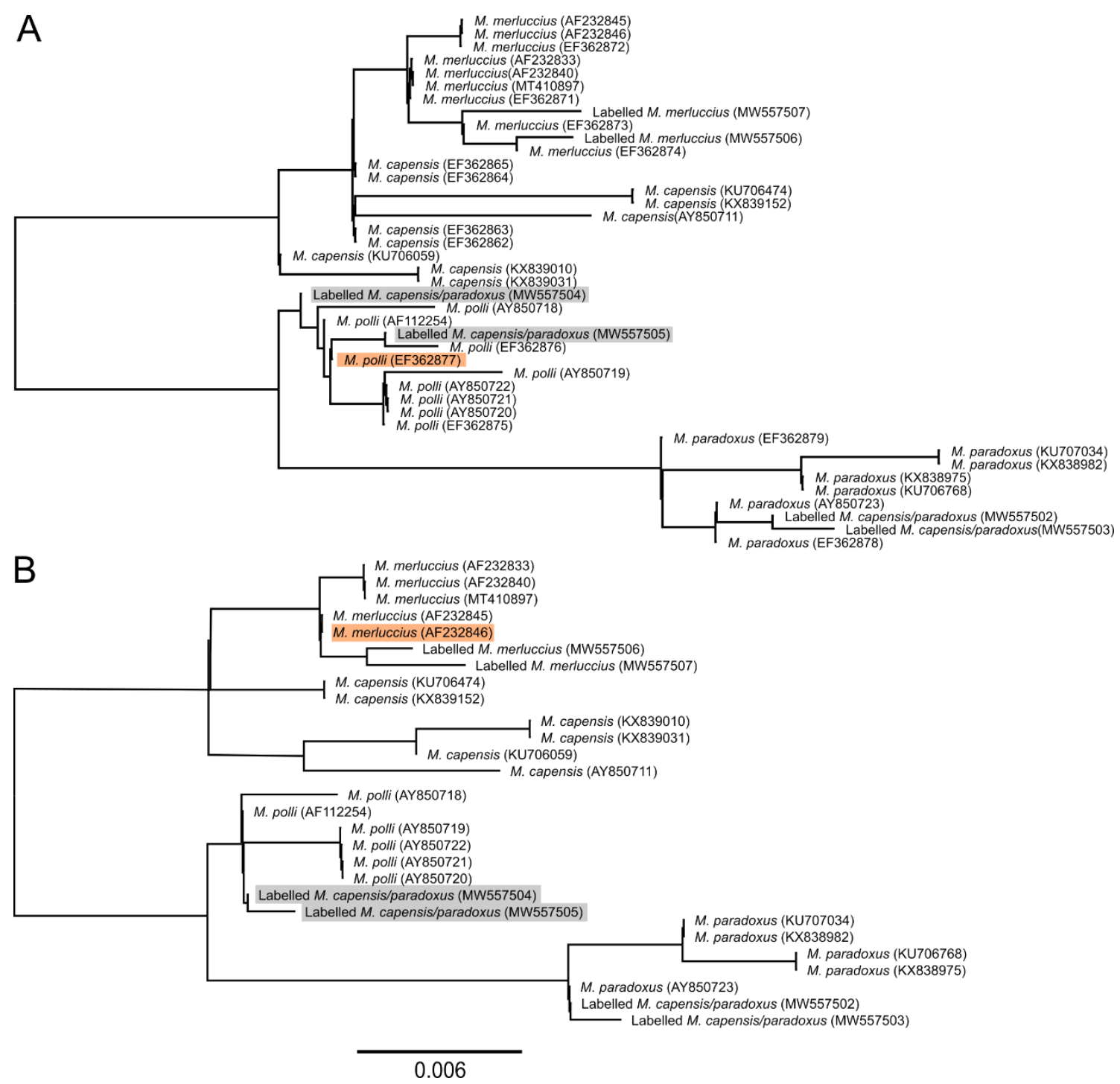

Figure 2. Maximum likelihood phylogenetic inference based on the mitochondrial control region (positions with less than 50\% missing data between positions 3 and 433 of EF362862) including all the available Merluccius identified sequences from Blanco-Fernandez, et al. ${ }^{1}$ (MW557502-7) and a representative subset of $M$. polli, M. capensis, M. merluccius and $M$. paradoxus sequences available in GenBank, both including (A) and excluding (B) those from Machado-Schiaffino, et al. ${ }^{13}$. Sequences to be authenticated and best overall BLAST hit in each case are shaded in grey and orange respectively. The tree is unrooted.

In addition to the above-highlighted potential problems derived from the use of BLAST for species assignment in seafood fraud studies, there is also the issue of contaminated sequences present in GenBank ${ }^{14}$. As an example, Blanco-Fernandez et al.'s work increase the contaminations in GenBank as they have contributed sequences whose taxonomic assignment has relied on best BLAST hit. As consequence of this, there are now three sequences of $T$. 
alalunga in GenBank labelled T. thynnus. These sequences, as well as those not obtained from morphologically identifiable specimens, should be retracted from GenBank to avoid further ramifications.

\section{Outlook}

In summary, we conclude that best BLAST hit cannot be used as evidence of fraud, and that studies on seafood authentication should consider the evolutionary context of the species under study. Not doing so can derive in serious consequences as illustrated by the problems we found in the work of Blanco-Fernandez et al., who base their strong claims on tuna mislabeling tends in Spain on erroneous taxonomic assignments.

\section{Methods}

Nucleotide sequences were downloaded from GenBank using provided accession numbers and aligned using ClustalW ${ }^{15}$. Positions with more than $50 \%$ of missing data were removed using Bioedit ${ }^{16}$ and used for building maximum likelihood phylogenetic trees using DNAML ${ }^{17}$. BLAST ${ }^{18}$ searches were performed against the NCBI nucleotide collection (nr/nt) using default parameters.

\section{Competing interests statement}

The authors declare no competing interests

\section{Data availability}

All data analysed for this reply have been downloaded from GenBank using the accession numbers provided in the Figures.

\section{Author contribution statement}

NDA and NRE conceived the idea, conducted the analyses, and wrote and edited the manuscript. 


\section{References}

1 Blanco-Fernandez, C. et al. Fraud in highly appreciated fish detected from DNA in Europe may undermine the Development Goal of sustainable fishing in Africa. Scientific Reports 11, 11423, doi:10.1038/s41598-021-91020-w (2021).

2 Lewis, S. G. \& Boyle, M. The Expanding Role of Traceability in Seafood: Tools and Key Initiatives. Journal of Food Science 82, A13-A21, doi:https://doi.org/10.1111/17503841.13743 (2017).

3 Hellberg, R. S., Pollack, S. J. \& Hanner, R. H. in Seafood Authenticity and Traceability (eds Amanda M. Naaum \& Robert H. Hanner) 113-132 (Academic Press, 2016).

4 Nakamura, I. \& Séret, B. Field identification key of tunas of the genus Thunnus. Cybium 26, 141-145 (2002).

5 Caruso, J. Lophiidae. Fishes of the North-eastern Atlantic and the Mediterranean 3, 1362-1363 (1986).

6 Viñas, J. \& Tudela, S. A Validated Methodology for Genetic Identification of Tuna Species (Genus Thunnus). PLOS ONE 4, e7606, doi:10.1371/journal.pone.0007606 (2009).

7 Alvarado Bremer, J. R., Viñas, J., Mejuto, J., Ely, B. \& Pla, C. Comparative phylogeography of Atlantic bluefin tuna and swordfish: the combined effects of vicariance, secondary contact, introgression, and population expansion on the regional phylogenies of two highly migratory pelagic fishes. Molecular Phylogenetics and Evolution 36, 169-187, doi:https://doi.org/10.1016/j.ympev.2004.12.011 (2005).

8 Díaz-Arce, N., Arrizabalaga, H., Murua, H., Irigoien, X. \& Rodríguez-Ezpeleta, N. RAD-seq derived genome-wide nuclear markers resolve the phylogeny of tunas. Molecular Phylogenetics and Evolution 102, 202-207, doi:https://doi.org/10.1016/j.ympev.2016.06.002 (2016).

9 Horoiwa, M. et al. Mitochondrial introgression by ancient admixture between two distant lacustrine fishes in Sulawesi Island. PLOS ONE 16, e0245316, doi:10.1371/journal.pone.0245316 (2021).

10 Shum, P. \& Pampoulie, C. Molecular identification of redfish (genus Sebastes) in the White Sea indicates patterns of introgressive hybridisation. Polar Biology 43, 1663-1665, doi:10.1007/s00300-020-02718-y (2020).

11 Espiñeira, M., González-Lavín, N., Vieites, J. M. \& Santaclara, F. J. Authentication of Anglerfish Species (Lophius spp) by Means of Polymerase Chain Reaction-Restriction Fragment Length Polymorphism (PCR-RFLP) and Forensically Informative Nucleotide Sequencing (FINS) Methodologies. Journal of Agricultural and Food Chemistry 56, 10594-10599, doi:10.1021/jf801728q (2008).

12 Aguirre-Sarabia, I. et al. Evidence of stock connectivity, hybridization, and misidentification in white anglerfish supports the need of a genetics-informed fisheries management framework. Evolutionary Applications 14, 2221-2230, doi:https://doi.org/10.1111/eva.13278 (2021).

13 Machado-Schiaffino, G., Martinez, J. L. \& Garcia-Vazquez, E. Detection of Mislabeling in Hake Seafood Employing mtSNPs-Based Methodology with Identification of Eleven Hake Species of the Genus Merluccius. Journal of Agricultural and Food Chemistry 56, 50915095, doi:10.1021/jf800207t (2008).

14 Steinegger, M. \& Salzberg, S. L. Terminating contamination: large-scale search identifies more than 2,000,000 contaminated entries in GenBank. Genome Biology 21, 115, doi:10.1186/s13059-020-02023-1 (2020).

15 Thompson, J. D., Higgins, D. G. \& Gibson, T. J. CLUSTAL W: improving the sensitivity of progressive multiple sequence alignment through sequence weighting, position-specific gap penalties and weight matrix choice. Nucleic Acids Research 22, 4673-4680, doi:10.1093/nar/22.22.4673 (1994).

Hall, T. (1999). 
17 Felsenstein, J. \& Churchill, G. A. A Hidden Markov Model approach to variation among sites in rate of evolution. Molecular Biology and Evolution 13, 93-104, doi:10.1093/oxfordjournals.molbev.a025575 (1996).

18 Altschul, S. F., Gish, W., Miller, W., Myers, E. W. \& Lipman, D. J. Basic local alignment search tool. Journal of Molecular Biology 215, 403-410, doi:https://doi.org/10.1016/S0022-2836(05)80360-2 (1990). 